
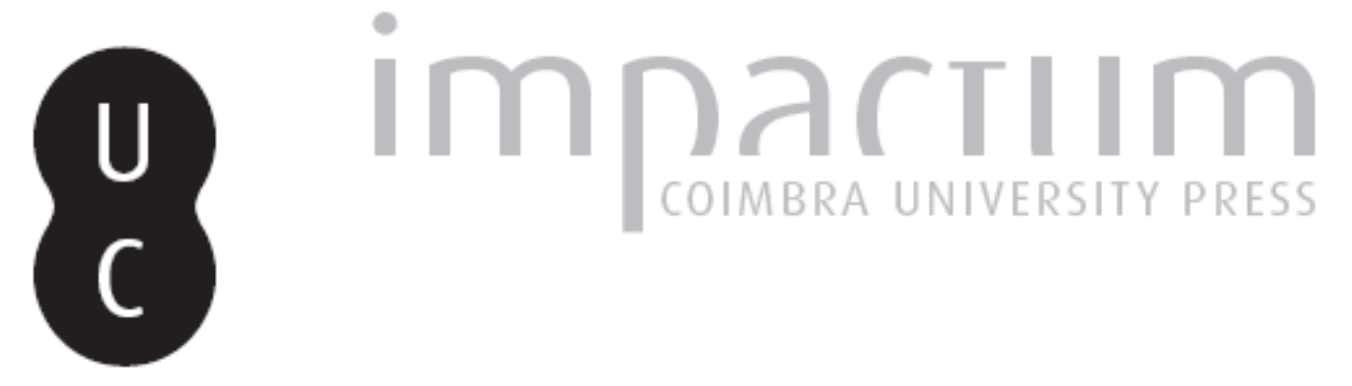

Dilatando a fé e o império: a imprensa na Guiné no colonialismo (1880-1973)

Autor(es): $\quad$ Fonseca, Isadora Ataíde

Publicado por: Imprensa da Universidade de Coimbra

URL persistente:

URI:http://hdl.handle.net/10316.2/39634

DOI:

DOI:http://dx.doi.org/10.14195/2183-5462_29_8

Accessed : $\quad$ 26-Apr-2023 16:37:31

A navegação consulta e descarregamento dos títulos inseridos nas Bibliotecas Digitais UC Digitalis, UC Pombalina e UC Impactum, pressupõem a aceitação plena e sem reservas dos Termos e Condições de Uso destas Bibliotecas Digitais, disponíveis em https://digitalis.uc.pt/pt-pt/termos.

Conforme exposto nos referidos Termos e Condições de Uso, o descarregamento de títulos de acesso restrito requer uma licença válida de autorização devendo o utilizador aceder ao(s) documento(s) a partir de um endereço de IP da instituição detentora da supramencionada licença.

Ao utilizador é apenas permitido o descarregamento para uso pessoal, pelo que o emprego do(s) título(s) descarregado(s) para outro fim, designadamente comercial, carece de autorização do respetivo autor ou editor da obra.

Na medida em que todas as obras da UC Digitalis se encontram protegidas pelo Código do Direito de Autor e Direitos Conexos e demais legislação aplicável, toda a cópia, parcial ou total, deste documento, nos casos em que é legalmente admitida, deverá conter ou fazer-se acompanhar por este aviso.

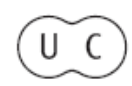




\section{Media Jornalismo}

\section{MÉDIA E COLONIALISMO(S)}




\title{
DILATANDO A FÉ E O IMPÉRIO: A IMPRENSA NA GUINÉ NO COLONIALISMO (1880-1973)
}

\author{
ENLARGING THE FAITH AND THE EMPIRE:THE PRESS IN \\ PORTUGUESE GUINEA THROUGHOUT COLONIALISM (1880-1973)
}

\author{
ISADORA DE ATAÍDE FONSECA ${ }^{1}$ \\ INVESTIGADORA INDEPENDENTE \\ 2825-017 - CAPARICA, PORTUGAL \\ IATAIDE@HOTMAIL.COM
}

\begin{abstract}
Resumo
Analisar a trajectória do jornalismo e as relações entre a imprensa o império na Guiné ao longo do colonialismo são os objectivos do artigo. 0 estudo adopta uma perspectiva multidisciplinar de investigação e análise, na qual a imprensa é observada na sua interdependência às dimensões política, económica e social. Aplicam-se as teorias do jornalismo em regimes liberais e autoritários para se observar a imprensa. 0 tardio surgimento da imprensa oficial reflectiu a fragilidade da presença portuguesa durante a Monarquia Constitucional. Ao longo da República a imprensa independente não se afirmou como espaço de debate público. No Estado Novo a imprensa serviu à propaganda do regime autoritário. Ao longo do colonialismo a imprensa na Guiné desempenhou o papel de apoiar e defender o império.
\end{abstract}

\section{Palavras-chave}

Guiné Portuguesa; colonialismo; imprensa; jornalismo; regimes políticos.

Abstract

The main goals of this article are to analyze the trajectory of journalism and the relationship between the press and the empire throughout colonialism in Portuguese Guinea. The study adopted a multidisciplinary perspective of research and analysis, in which the press is seen in their interdependence to the political, economic and social dimensions. To observe the journalistic performance this research applied the theories of journalism in liberal and authoritarian regimes. The late emergence of the official press reflected the fragility of the Portuguese presence during the Constitutional Monarchy. Along the Republic's the independent press did not asserted as a space for public debate. In the Estado Novo the press was used to the propaganda of the authoritarian regime. Throughout colonialism the press in Guinea played the role of supporting and defending the Portuguese Empire.

KEYWORDS

Portuguese Guinea; colonialism; press; journalism; political regimes.

1 A autora agradece os valiosos comentários do revisor anónimo, os quais enriqueceram este artigo. 
A revolução liberal na década de 1820, a independência do Brasil e a crise económica estão entre os factores que levaram as elites portuguesas a repensar e reforçar as suas políticas em África (Alexandre, 1998). Para estimular o desenvolvimento das suas colónias africanas o governo monárquico liberal publicou nova legislação em 1836, a qual incluía a publicação de boletins informativos, o que levou ao desembarque da imprensa na África portuguesa.

Analisar o desenvolvimento do jornalismo, reflectir sobre as relações entre o império e a imprensa e produzir uma síntese da trajectória da imprensa periódica na Guiné são os objectivos deste artigo. Da observação do percurso da imprensa na Guiné emerge o problema da incipiência da actividade jornalística no período colonial se comparada a outras colónias portuguesas em África. Deste modo, na procura de compreender os factores que levaram ao fraco protagonismo da imprensa na Guiné, o estudo adopta uma perspectiva comparada aos demais territórios portugueses em África.

A presente investigação contribui com a história da imprensa na Guiné, embora esta esteja por ser feita. ${ }^{2}$ Porém, trata-se sobretudo de uma análise para a síntese das relações entre a imprensa e o império ao longo do colonialismo português, contribuindo para os estudos da imprensa nos contextos lusófonos e constituindo-se enquanto dimensão privilegiada da investigação colonial. Adoptou-se uma perspectiva de investigação multidisciplinar que incluiu as dimensões política, económica e social, seguindo-se o conselho de Porter (2011: 181). A pesquisa empírica seguiu princípios analíticos e metodológicos multidisciplinares e multicausais, valorizando os processos sociais "enquanto resultados de múltiplas redes sócio-espaciais interligadas e sobrepostas de poder económico, ideológico, militar e político", como sugerido por Jerónimo (2011: 32-33).

0 estudo abrange um período de 93 anos, entre o surgimento do boletim oficial, em 1880, e a independência da Guiné, em 1973. Tais marcos, além de abrangerem a trajectória da imprensa no período colonial, permitem a observação das rupturas e das continuidades entre as distintas etapas e regimes políticos do colonialismo português.

Na observação do desempenho da imprensa, procura-se superar uma análise "tradicional" - na qual o jornalismo desempenha os papéis de estabilizar e manter a ordem nos regimes autoritários e é o garante das liberdades nas democracias (Gunther e Mughan, 2000:3-4). Para tal, aplicam-se teorias do jornalismo e dos media em regimes liberais e autoritários. As teorias desenvolvidas por Christians et al. (2009: 30-31) que assinalam os papéis monitor, facilitador, radical e colaborador como característicos das democracias, são aplicadas neste estudo. Para se pensar sobre a imprensa em períodos autoritários aplicou-se a perspectiva de Siebert et al. (1963: 28) na qual "o primeiro dever da imprensa é o de evitar interferência com os objectivos do Estado". ${ }^{3}$

2 A história da imprensa na Guiné ao longo do período colonial recebeu escassa atenção, o único estudo conhecido é o de José J. Gonçalves, A Informação na Guiné, em Cabo Verde e em São Tomé e Príncipe (Achegas para o seu estudo), 1966. Sobre a imprensa na África portuguesa, incluindo um estudo de caso da Guiné Portuguesa, assinala-se a tese de doutoramento de Isadora de Ataíde Fonseca, A Imprensa e o Império na África Portuguesa (1842-1974), 2014.

3 Todas as citações traduzidas são de responsabilidade da autora do artigo. 
Para se analisar o sistema de imprensa, o trabalho tem como referência as dimensões desenvolvidas por Hallin e Mancini (2004: 21-44), bem como inclui as críticas e revisões deste campo teórico (Hallin e Mancini, 2012). Assim, a sistematização do legado do sistema de imprensa inclui as seguintes dimensões: 1) desempenho dos papéis jornalísticos; 2) estrutura de mercado; 3) profissionalismo; 4) paralelismo político e 5) intervenção do Estado.

Ao longo do artigo descrevem-se conteúdos seleccionados da imprensa periódica como estratégia para se demonstrar os papéis desempenhados pelo jornalismo e as características do sistema de imprensa, bem como para se salientar as relações entre a imprensa e o seu contexto sociopolítico colonial.

\section{Monarquia e Imprensa Oficial}

A situação portuguesa na Guiné no século XIX divide-se em dois períodos. 0 primeiro estendeu-se a 1859 e caracterizou-se pela interdição do tráfico de escravos a norte do Equador e pelas tentativas de reconversão económica do comércio negreiro. No segundo período procurou-se afirmar a soberania portuguesa, o que exigiu a construção de um aparelho de Estado, fase que se encerrou com as campanhas militares de 1912-15 (Silveira, 1998: 213).

Desde meados do século XV comerciantes portugueses e colonos cabo-verdianos estão instalados nas regiões costeiras da Guiné e miscigenados aos povos locais. A presença portuguesa e luso-africana caracterizou-se pela informalidade e pela iniciativa privada. Os luso-africanos controlaram o tráfico de escravos e o poder político até meados do século XIX, e o envolvimento das autoridades públicas nas actividades comerciais ajuda a explicar o fraco poder político do governo (Soares, 2000).

A desagregação dos impérios autóctones; os conflitos étnicos e a imposição do islamismo aos povos animistas; as tentativas de dominação europeia e as intrigas; a inexistência de uma língua franca e o destaque social dos crioulos caracterizaram a situação da colónia quando o governo metropolitano decidiu autonomizar a Guiné de Cabo Verde, em 1879, dando ao território governador e instituições próprios, com Bolama como capital (Silva, 2010: 22-23).

A Imprensa Nacional instalou-se em 1880 e com ela iniciou-se a publicação do boletim oficial no mesmo ano. Semanário e com quatro páginas, o Boletim Oficial da Guiné (BO) seguiu o padrão das demais colónias, dividido entre Parte Oficial e Não Oficial. A edição n 26, de Julho de 1886, publicava o relatório da junta de saúde de Bissau, o qual garantia que "Os gentios da Guiné, com quanto selvagens, são susceptíveis de se converterem ao cristianismo".

Na década de 1880 o problema dos limites territoriais com a França resolveu-se com o tratado assinado em 1886, no qual Portugal cedeu territórios mas obteve vantagens na sua pretensão de um 'mapa cor-de-rosa' em África. Quanto a economia, o cultivo do amendoim foi o foco da reconversão económica da colónia, e a produção e a exportação cresceram entre 1840-80 tendo sido acompanhadas pelo predomínio francês no negócio (Forrest, 1992: 16-17).

Ao longo dos anos o Boletim Oficial incluiu o relatório dos concelhos de Bolama e Bissau, e 0 n 02 de 1891, de Janeiro, referia que a situação sanitária de Bissau era "sofrível", o estado comercial "pouco animado", o sossego público "não foi alterado" e as obras municipais eram "nenhumas". 
Foi a partir da década de 1890 que os conflitos militares agravaram-se. Em Abril de 1891, os portugueses foram derrotados em Bissau e, entre 1892-95, a Guiné tornou-se um distrito militar. Pélissier (1989: 114-119) registou 21 acções militares portuguesas contra os africanos entre 1891-1908 e considerou que nesta etapa a conquista estava a "meio caminho".

0 BO retratava as accções políticas, económicas e militares da Guiné, bem como 0 quotidiano da colónia. Em 1905, n 12 de Março, o Boletim noticiava as obras públicas em Bissau. Em 1907, n 22 do BO, a repartição da fazenda do concelho de Cacheu reclamava que os contribuintes têm "deixado de cumprir em seu tempo com as obrigações". A relação dos régulos e chefes de tabanca que foram cumprimentar o governador em Julho de 1909 foi publicada na edição $n^{0} 33$, de Agosto, a qual relatava que cerca de trezentas lideranças africanas tinham ido a Bolama saudar o governador, que recebeu um dente de marfim de sete quilos e 200 cabeças de gado.

\section{A AUSÊNCIA DA IMPRENSA NÃO-OFICIAL}

Como se explica que na Guiné não tenha emergido uma imprensa periódica privada, não-oficial, ao longo da Monarquia? A inexistência de autoridade portuguesa sobre as populações nativas, o regime de administração indirecta e a multiplicidade de unidades políticas nativas, e a inexequibilidade das reformas administrativas são os factores que caracterizam o estatuto político da Guiné no século XIX e ajudam a compreender a ausência da imprensa noticiosa, generalista e independente (Silva, 2010: 24).

Após a implantação do boletim oficial nas colónias africanas seguiu-se a emergência da imprensa privada. Em geral, tal imprensa apoiava o projecto colonial e 0 governo metropolitano, ainda que fosse crítica das administrações locais. Ou seja, na sua primeira fase a imprensa caracterizou-se por traduzir os conflitos entre as elites europeias no espaço colonial. Em Cabo Verde o boletim foi implementado em 1842 e o primeiro jornal não-oficial, O Independente, surgiu em 1877. Em Angola, 0 boletim começou a ser impresso em 1845, e, em 1866, apareceu a imprensa independente com A Civilização Portuguesa. ${ }^{4}$ Em Moçambique, foi em 1854 que foi impresso o primeiro número do boletim e, em 1877, circulava a imprensa não-oficial, 0 Africano. ${ }^{5}$ Por fim, em São Tomé e Príncipe, saiu em 1857 o boletim oficial e, em 1869, publicava-se 0 Equador, primeiro jornal independente.

A emergência da imprensa não-oficial dependeu das elites europeias ou luso-africanas nos territórios. Entretanto, foi necessário a tais elites um conjunto de recursos para concretizar a imprensa, entre eles: a existência de tipografias; os meios financeiros para reproduzir os títulos; pessoas com formaç̧ão e interesse para actuar como jornalistas; e uma elite intelectual interessada nos assuntos públicos conjuga-

4 Aurora foi o primeiro jornal não-oficial em Angola, contudo, visto seu carácter literário e sua efemeridade, considera-se como marco da imprensa independente A Civilização Africana. Sobre a imprensa em Angola ver Júlio C. Lopo, Jornalismo de Angola, Subsídios para a sua História (1964).

50 Progresso, em 1868, é o primeiro jornal independente em Moçambique. Contudo, visto ter tido

apenas uma edição, considera-se como marco da imprensa independente o jornal 0 Africano. Sobre a imprensa em Moçambique ver llídio Rocha, A Imprensa de Moçambique (2000). 
da à existência de um espaço público de discussão - em geral, tais espaços foram meios e associações culturais, comerciais, profissionais e nativas. ${ }^{6}$

Dependentes do governo de Cabo Verde até 1880, as instituições da administração pública tardaram na Guiné e a sua implementação coincidiu com a decadência das elites luso-africanas. Seguiu-se o predomínio dos investimentos estrangeiros nas explorações agrícolas e comerciais. Ou seja, além da escassez de colonos portugueses na Guiné, estes eram fracos do ponto de vista económico, não tinham força política para defender os seus interesses nem recursos para promover o jornalismo. Assim, as dinâmicas políticas associadas aos aspectos económicos foram decisivas para inibir a emergência da imprensa privada na Guiné, nas demais colónias associadas às elites portuguesas. ${ }^{7}$

A afirmação das instituições governativas na Guiné coincide com o acirrar dos conflitos militares, o que levou ao predomínio de uma elite militar que tinha como prioridade a 'pacificação'. No caso da Guiné, a luta portuguesa pelo domínio do território e pela subjugação dos povos africanos parece ter reduzido os conflitos entre elites coloniais em relação ao governo, à administração e à economia. Logo, a existência da imprensa não era um imperativo para as elites e os seus recursos estavam voltados para o domínio do território.

Eram escassos os colonos portugueses e europeus, a maioria da população africana vivia fora do espaço urbano e não tinha acesso aos elementos e estruturas características da modernidade. Sobressai na Guiné a inexistência de uma elite intelectual articulada em espaços culturais e associativos. Tais factores contribuíram para a fraqueza do espaço público local, pois era reduzido o potencial público leitor, bem como os eventuais jornalistas ou empreendedores da imprensa.

Ao longo da Monarquia, o Boletim Oficialfoi o único meio de informação na Guiné e exerceu sobretudo o papel colaborador. A colaboração refere-se à relação directa entre a imprensa e o governo e implica que a informação corrobore as políticas e práticas do regime para que as metas deste sejam atingidas (Christians et al., 2009: 197).

\section{República: Imprensa EfÉmera}

A herança da Monarquia em África eram territórios 'atrasados' que enfrentavam a resistência da população autóctone. No entanto, o foco em civilizar, colonizar e produzir, princípios culturais e económicos da Monarquia, transitaram para a República. 0 regulamento de 1911 manteve 0 trabalho obrigatório e o recrutamento forçado para as obras públicas. A colecta de impostos era a forma mais directa de exploração do povo e os africanos continuaram a não ser cidadãos. Os indígenas

6 Por exemplo, em Cabo Verde as sociedades culturais precederam e alavancaram o surgimento da imprensa. Sobre a imprensa em Cabo Verde ver João N. de Oliveira, A Imprensa Cabo-Verdiana (1998). Em Moçambique, organizações operárias e indígenas foram proprietárias de jornais, ver José Capela, "A imprensa de Moçambique até à Independência" (1996).

7 Em São Tomé e Príncipe, o surgimento do Equador, em 1869, esteve associado aos interesses comerciais e agrícolas da colónia, ver José J. Gonçalves, A Informação na Guiné, em Cabo Verde e em São Tomé e Príncipe... Em Moçambique, o surgimento de 0 Africano esteve vinculado aos interesses agrícolas e aos conflitos políticos na Zambézia, ver llídio Rocha, A Imprensa em Moçambique. Em Angola, o surgimento de A Civilização da África Portuguesa esteve associado aos interesses económicos, mercantis e agrícolas, ver Júlio C. Lopo, Jornalismo de Angola... 
eram considerados todos os indivíduos de cor naturais da província que não tivessem alcançado o uso pleno dos direitos civis e políticos conferidos aos cidadãos portugueses (Marques, 2001: 26). A libertação do modelo mercantilista e a fixação de colonos europeus eram as linhas mestras do governo republicano. Contudo, os défices coloniais e uma burguesia metropolitana que lucrava com as práticas mercantilistas inviabilizaram tal projecto (Proença, 2009).

A colonização europeia em África caracterizou-se pela dualidade e por uma governação bifurcada, na qual as administrações directas e indirectas foram complementares no controlo dos povos nativos. Em suma, "os poderes coloniais generalizaram um despotismo descentralizado como a sua principal resposta a questão nativa" (Mamdani, 1998: 18). 0 colonialismo português também foi bifurcado e dual, consagrou-se na divisão indígena e não-indígena, visava garantir a exploração dos territórios e manifestava-se nas relações sociais, na divisão do trabalho e na distribuição dos privilégios (Cabaço, 2010: 36).

Neste cenário, para além da resistência indígena à ocupação, a constituição da Liga Guineense, em 25 de Dezembro de 1910, surge como uma resposta às dualidades do poder colonial e assinala os conflitos entre europeus, Grumetes (descendentes de antigos escravos e de grupos africanos convertidos ao cristianismo) e africanos. A organização assumia a defesa dos seus membros, propunha-se a criar escolas e a trabalhar para o progresso e 0 desenvolvimento da Guiné. Não há registo de que a Liga tenha reivindicado a independência ou a autonomia do território e, se a associação criticava o governador, não punha em causa a sua legitimidade. No entanto, a Liga esteve filiada no Partido Republicano Democrático e atacou a corrupção e os abusos de autoridade. Embora alguns membros da Liga criticassem as acções militares contra os africanos, em geral a Liga Guineense apoiou o governador devido aos seus interesses económicos e ofereceu Grumetes para as lutas de pacificação e conquista até 1913 (Fonseca e Oliveira, 1911; Fonseca, 1912; Pélissier, 1989; Mendy, 1994; Sousa, 2012). Deste modo, diferente do que se passou nas demais colónias portuguesas em África, na Guiné nem as elites africanas nem as organizações nativas desempenharam um papel forte de reivindicação e protesto. ${ }^{8}$

Nesta altura, o Boletim Oficial continuava como o único canal de informação impressa na Guiné e os conflitos entre africanos e portugueses agravavam-se. José Teixeira Pinto foi o chefe do Estado-Maior entre 1913-1915 e o responsável pela 'pacificação' da Guiné. "Achando-se há muito tempo em estado de rebelião os indígenas da Ilha de Bissau [...] É declarado o estado de sítio em toda a Ilha", anunciou 0 suplemento ao Boletim $\mathrm{n}^{0}$ 20, de Maio de 1915. Teixeira Pinto exigia que os Papéis (etnia africana da Guiné) entregassem suas armas e pagassem impostos. A Liga Guineense trabalhava no mesmo sentido e promoveu contactos com os régulos da ilha e com o governo e os militares, em Março de 1915, para evitar a guerra. Con-

8 Sobre as elites nativas e o proto-nacionalismo na África portuguesa, ver Mário P. de Andrade, Origens do Nacionalismo Africano (1998). Sobre as elites nativas em Angola, ver Marcelo Bittencourt, Dos Jornais às Armas (1999). Sobre as elites nativas em Moçambique, ver Aurélio Rocha, "0 Pan-Africanismo em Moçambique (1900-1930)" (2000). Sobre as elites nativas cabo-verdianas, ver José C.G. dos Anjos, Intelectuais, literatura e poder em Cabo Verde - lutas pelas definição da identidade nacional (2006). Sobre as elites nativas são-tomenses ver Augusto Nascimento, "A Liga dos Interesses Indígenas de S. Tomé e Príncipe (1910-1926)" (1999). 
tudo, as negociações falharam e os portugueses avançaram contra os Papéis e os Grumetes. 0 conflito estendeu-se a 20 de Julho e, em 16 de Agosto de 1915, a Liga Guineense foi dissolvida pelo governador Oliveira Duque devido à 'insubordinação'.

Apesar dos conflitos, os primeiros anos da República promoveram algum desenvolvimento na Guiné, com a melhoria das comunicações e 0 acréscimo de obras públicas. 0 Ecos da Guiné, Quinzenário Independente Defensor dos Interesses da Província, saiu em Bolama no dia 02 de Janeiro de 1920. Propriedade da empresa Ecos da Guiné, foi dirigido por José Joaquim Curvo Semedo e tinha como editor Carlos Valentim Mendes, também director da Imprensa Nacional. 0 jornal foi uma iniciativa de funcionários públicos europeus e era reproduzido na tipografia do Estado, porém, não sobreviveu ao primeiro trimestre de 1920. A Voz da Guiné, em 1922, escreverá que o Ecos da Guiné "quase que morreu a nascença, porque a verdade é que, para viver, teria que se sujeitar a imposições do governo".

"Levar longe o conhecimento do nosso mercado [...] inspeccionar todos os ramos de administração pública para que as leis se cumpram integralmente como nelas se contêm, combater as infracções, defender a justiça e o direito", eram os fins do jornal, assumidos no seu $n^{0} 01$. A mesma edição garantia que as colunas do periódico estavam abertas a todas "às consciências limpas", desde que houvesse "parcimónia, e nunca visando questões políticas". 0 n 04 do Ecos da Guiné sublinhava que "pusemos de parte todos os intuitos mercantilistas que acaso pudessem haver numa empresa jornalística". Na edição n ${ }^{0}$ 07, último número do jornal, o Ecos da Guiné dizia que estava a trabalhar em prol da colónia, porém, "não tem sido assim compreendido o nosso fim".

"Porque isto não caminha" foi uma das rubricas de opinião do Ecos da Guiné, a qual foi crítica das políticas e acções metropolitanas em relação à colónia. Por exemplo, no $\mathrm{n}^{0}$ 01, abordava o problema da instabilidade dos governadores como resultado da "trica" política. No $n^{0}$ 03, a coluna observava que "0 Ministério das Colónias tem muitos afilhados que contentar [...] Para se mascarar um pouco essa padrinhagem, mandam-nos prestar serviços nas colónias". A edição n ${ }^{0} 04$ publicou uma carta ao ministro das colónias, apontando que o estado da Guiné não permite uma "categoria na escala da civilização". 0 n 06 voltava à carga, reclamando que o plano de fomento para a colónia "há largo tempo demora pelo Ministério das Colónias, certamente esquecido". Na sua curta existência, o Ecos da Guiné tratou ainda de diversos temas sociais, entre eles: a situação dos funcionários públicos; a fome em Bolama; a falta de transporte marítimo; o regime de trabalho de oito horas; 0 custo das rendas e a falta de moradias em Bissau e Bolama.

Em 06 de Abril de 1922 saiu o nº 01 de A Voz da Guiné, Quinzenário Republicano Independente. 0 jornal tinha como editor Rui Carrington S. da Costa e como redactor principal José Lourenço da Conceição Leitão, presidente da comissão municipal de Bolama, e também foi reproduzido na Imprensa Nacional. Efémero, conhecem-se apenas 11 números. $0 n^{0} 01$ declarava que "Não nos movem intuitos polemistas nem nos apaixonam as lutas partidárias".

0 jornal foi fiel ao governador e $0 \mathrm{n}^{0} 05$ sublinhava como "falsos" os ataques que lhe eram feitos: "Sua Exma não faz guerra aos pretos, nem aos caboverdianos [...] quer que nela [na província] se acentue, de vez, o domínio português que tão abalado está". No n 07 , em Junho, quando das comemorações públicas do primeiro ano de governo de Velez Caroço, o jornal assumiu que "A Voz da Guiné defende, é 
verdade, a política do governo, mas defende-a porque tem encontrado nessa política uma política honesta e com fim útil à província: o seu saneamento". Em mais uma declaração de apoio ao governo, o jornal saudava a retomada das eleições municipais no $\mathrm{n}^{0} 11$, "mais uma tradição inaugurada pelo governador".

Embora apoiasse o governo, A Voz da Guiné não deixou de apontar alguns dos problemas do território: a jornada de oito horas e o descanso semanal; as dificuldades estruturais de Bolama; a prostituição; 0 trabalho indígena; a educação; 0 custo de vida e 0 transporte.

Em 17 de Agosto de 1924, em Bissau, saiu o no 01 do Pró-Guiné, Órgão do Partido Republicano Democrático, que tinha como proprietário, editor e redactor principal Francisco da Veiga. Reproduzido na Imprensa Nacional, propunha-se a quinzenário, porém editou apenas quatro números. $0 \mathrm{n}^{0} 01$ explicava os objectivos do jornal e reconhecia o trabalho do governador:

defender os interesses da pátria e da república [...] Não faltará quem diga, porque os maldizentes são muitos, como já disseram de A Voz da Guiné, falsamente, que o Pró-Guiné será um caudatário do Palácio do Governo e receberá dali inspiração para se conduzir. Não seria desdouro para nós que assim sucedesse, actualmente, porque à testa da administração superior da Província está um homem honesto, digno e pundenoroso [Velez Caroço].

0 jornal afirmava estarem à frente das administrações municipais "homens de prestígio". 0 problema do transporte marítimo continuava na agenda, "mas o governador tem feito todos os esforços para resolver a situação". As crises alimentares de Cabo Verde e a falta de mantimentos na Guiné foram outro tema do Pró-Guiné, que acusava os cabo-verdianos de serem os responsáveis pelos altos preços dos alimentos ( $n^{0}$ 02). A propósito de um artigo "anti-patriótico" publicado na Gazeta das Colónias, que circulava em Lisboa, o Pró-Guiné argumentava que a Guiné "é muito fértil e causa pena vê-la sem qualquer progresso agrícola [...] há concessões de terrenos mas estes não são explorados". A última edição conhecida do Pró-Guiné é de 25 de Dezembro de 1924, número dedicado ao IV centenário da morte de Vasco da Gama.

No fim da década de 1920, a Guiné tinha avançado na urbanização, embora os serviços socias permanecessem mínimos. No campo económico, a agricultura e 0 comércio persistiam como dominantes, existiam poucas companhias de exploração europeias e todas sofriam dificuldades financeiras.

\section{JORNALISMO COLABORADOR}

Depois de 40 anos da implantação do Boletim Oficial apareceu na Guiné o primeiro jornal generalista e noticioso não-oficial, o Ecos da Guiné. Contudo, a imprensa não se consolidou e não surgiram títulos com distintas orientações políticas, como aconteceu nas demais colónias portuguesas em África. A fraqueza das elites na Guiné, o incipiente desenvolvimento económico e social da colónia e o prolongamento das guerras de 'pacificação' ao longo da República permaneceram como factores que inibiram o surgimento de uma imprensa política que representasse os grupos sociais em conflito. 
A efemeridade e 0 apoio ao governo local são as características mais salientes da imprensa da época. Os três jornais foram iniciativas de funcionários públicos, pequenos comerciantes e políticos locais que dependiam da Imprensa Nacional para reproduzir os periódicos. Os vínculos profissionais, políticos e económicos que ligavam os fundadores dos jornais ao governo colonial explicam o suporte que os três títulos deram aos governadores, ainda que apontassem as deficiências no desenvolvimento da Guiné e reivindicassem maior protagonismo do governo metropolitano. Deste modo, o papel jornalístico colaborador continuou a preponderar, como tinha acontecido durante a Monarquia. Contudo, nota-se que 0 Ecos da Guiné procurou exercer o papel monitor, o qual implica um explorar do mundo, das suas condições e dos seus eventos aliado à interpretação dos factos com critérios de relevância pública (Christians et al., 2009: 140). 0 jornal ensaiou a fiscalização e as críticas ao poder público e privado, contudo, como indicou A Voz da Guiné, tal levou ao seu fim precoce.

Ao longo da República também não apareceu na Guiné um jornal africano, que defendesse os interesses dos povos nativos, como aconteceu nas demais colónias portuguesas em África. ${ }^{9}$ As relações da Liga Guineense com o governo e a sua dissolução precoce dificultaram o protagonismo da organização. Na Guiné o desenvolvimento de uma elite africana foi incipiente, e foi este grupo - em geral educado, com postos na administração pública ou propriedades comerciais e agrícolas, e articulado em organizações africanas e republicanas - que promoveu os jornais africanos que desempenharam um papel jornalístico radical nas demais colónias na Monarquia e na República. ${ }^{10}$

A propriedade da imprensa esteve ligada apenas às elites portuguesas, mas estas não foram capazes de consolidar os seus jornais. Sublinhe-se que na Guiné não há indícios da existência da maçonaria no período monárquico ou republicano, e que esta organização foi importante na criação de jornais nas demais colónias portuguesas. ${ }^{11}$

0 Estado teve uma intervenção forte na imprensa e dele dependeu a impressão dos jornais. Quando a imprensa ensaiava a crítica à administração, os jornais deixavam de existir e os indicadores apontam para o controlo dos conteúdos pelo governador. É difícil aplicar a dimensão do paralelismo político na Guiné, porque não houve qualquer diversidade e pluralidade na imprensa, e este representou apenas os interesses dos governos da colónia. Quanto aos jornalistas, sabe-se que estes eram funcionários públicos, políticos e comerciantes; não dependiam de rendimentos financeiros da actividade jornalística e actuavam como advogados do governo local.

9 Sobre a imprensa nativa e africana em Cabo Verde, ver Manuel B. Semedo, Cabo Verde: A Construção da Identidade Nacional, Análise da Imprensa entre 1877 e 1975(2003). Entre os jornais defensores dos africanos em São Tomé e Príncipe, A Verdade (1911), A Liberdade (1920-1924) e 0 Combate (1925). Sobre a imprensa nativa e africana em Angola, ver Maria C. P. Ribeiro, Ideias republicanas na consolidação de um pensamento angolano urbano (1880 c.-1910 c.): convergência e autonomia(2012). Sobre a imprensa nativa e africana em Moçambique ver Vladimir D. Zamparoni, "A Imprensa Negra em Moçambique: A Trajetória de "0 Africano" - 1908-1920" (1988).

10 Como exemplo o caso de Moçambique, ver Jeanne M. Penvenne, “João dos Santos Albasini (1876-1922): The Contradictions of Politics and Identity in Colonial Mozambique" (1996).

11 Sobre a história da Maçonaria em Portugal e na África Portuguesa ver A.H. de Oliveira Marques, História da Maçonaria em Portugal, 1990. 
Estado Novo, Imprensa Instrumental

A incapacidade da República em desenvolver uma política colonial coerente é apontada como um factor decisivo para o golpe militar de 28 de Maio de 1926 (Alexandre, 1993: 123-24). A partir de 1930, António de Oliveira Salazar assumiu o ministério das colónias para estender o equilíbrio financeiro alcançado na metrópole ao ultramar. No âmbito das novas políticas, o Acto Colonial, em Abril de 1930, que resguardou a soberania portuguesa em África e promoveu a reorganização administrativa.

Com as políticas centralizadoras do governo autoritário, os portugueses dominaram o comércio na Guiné, tendo à frente o Banco Nacional Ultramarino e a Casa Gouveia. As finanças da colónia dependeram dos recursos metropolitanos e dos aumentos dos impostos. 0 governador concentrou os poderes, com um conselho consultivo de seis membros, um secretariado permanente e 14 órgãos de serviços públicos. 0 regime do indigenato foi instituído em 1928 e distinguiu assimilados e africanos, embora desde 1917 já se diferenciassem formalmente os civilizados dos não-civilizados. ${ }^{12}$

Em 1930, surgiu em Bissau a primeira tipografia privada e entre 1930-31 foram publicados 20 números do Comércio da Guiné, órgão dos interesses económicos da colónia. ${ }^{13} 0$ jornal foi dirigido por Armando António Pereira, advogado nativo, militante da Liga Africana e representante da Guiné na organização nas décadas de 1910-20 (Andrade, 1998: 203). ${ }^{14} 0$ último exemplar do jornal saiu em 18 de Abril e coincide com a eclosão de um movimento insurrecto na Guiné. ${ }^{15}$ Em 1941 a capital da Guiné mudou de Bolama para Bissau e houve uma reorganização da burocracia administrativa.

Arauto, Dilatando a fé e o império, foi um mensário que apareceu em Maio de 1943, dirigido pelo Padre Afonso Simões e reproduzido na Imprensa Nacional. 0 n 01 declarava que "dilatando a fé, é nosso desejo, concomitantemente, dilatar o império também, interessando-nos por tudo o que diga respeito ao desenvolvimento e progresso desta colónia". 0 n 14, de Junho de 1944, garantia que "Portugal prossegue [...] a sua obra de reconstrução nacional que tem sido a preocupação dominante daqueles que dirigem os altos destinos da nação".

Também atento as políticas locais, os $n^{\text {os }} 41$ e 42, de 1946, do Arauto relatavam a $1^{\text {a }}$ Conferência dos Administradores da Guiné, a qual identificou como principais problemas da colónia a dificuldade de colaboração dos cipaios como elos entre au-

12 Sobre a cidadania nas colónias portuguesas ver Cristina N. da Silva, Constitucionalismo e Império, A Cidadania no Ultramar Português (2009).

13 Embora a Biblioteca Nacional de Portugal tenha alguns números do jornal na sua colecção, estes não estão disponíveis devido ao seu mau-estado.

14 Mário P. de Andrade refere que o jornal chamava-se 0 Correio da Guiné, porém, tal parece um equívoco visto que não há indícios da existência de tal título e que no catálogo da Biblioteca Nacional de Portugal Armando António Pereira consta como director de Comércio da Guiné. 0 título também aparece no trabalho de José J. Gonçalves, A Informação na Guiné, em Cabo Verde e em São Tomé e Príncipe..., 1966.

15 A 17 de Abril de 1931 um movimento 'reviralhista' (ligado à resistência na ilha da Madeira, conhecida como 'Revolução Triunfante') levantou-se em Bolama. 0 chefe do estado-maior, alguns oficiais e o governador foram presos e embarcados para Lisboa e formou-se uma junta governativa. No princípio de Maio, o movimento dilui-se e os seus chefes foram presos. Ver Réne Pélissier, História da Guiné - portugueses e africanos na senegâmbia, 1989. 
toridades e indígenas; a obrigação dos nativos trabalharem; as irregularidades na cobrança do imposto da palhota e os problemas infra-estruturais.

Em Janeiro de 1947, o ${ }^{0} 45$ trazia o discurso do governador Sarmento Rodrigues na abertura da exposição de Bissau: "Nesta terra portuguesa há união de almas e boas vontades, há trabalho, há sacrifício, há entranhado amor ao engrandecimento de Portugal". 0 governo de Sarmento Rodrigues coincide com o apogeu do colonialismo na Guiné e priorizou o desenvolvimento da administração colonial, a participação dos assimilados e um tratamento paternalista para com os indígenas, e a construção de uma rede de infra-estruturas (Silva, 2008).

Entre 1950-54, a Secção Técnica de Estatística do governo publicou o mensário Ecos da Guiné. Foi um periódico oficial de divulgação das actividades do governo, com textos escritos pelos funcionários públicos e que exaltava a acção colonial na Guiné.Em 1950, o Arauto tornou-se diário e passou a ter como director o Padre José Maria da Cruz. As notícias da metrópole continuaram com destaque no diário, que no seu $n^{0} 1415$, de Janeiro de 1952, relatava que foram presos os organizadores duma "conjura contra a segurança do Estado". Na época as notícias internacionais não incluíam os territórios e países africanos e as informações locais eram escassas. Em Fevereiro de 1953, n 1813, o Arauto assinalava a nomeação de Marcello Caetano como vice-presidente do Conselho Ultramarino. Seguindo uma linha de despolitização, 0 mundial de futebol e 0 dia das forças aéreas eram os destaques da edição n ${ }^{0}$ 2297, de Julho de 1954, numa tendência que se manteve.

A Guiné recebeu "com delirante patriotismo e entusiástica vibração" o presidente da República em Maio de 1955, noticiava o Arauto. 0 jornal, que até então era reproduzido em duplicador, passava a circular em formato de imprensa e um texto apontava o Arauto como "Um jornal diário autêntico, com artigos de análise, com crítica e interesse público".

0 que o governo colonial e metropolitano não sabiam e o Arauto não noticiou foi a criação do Partido Africano da Independência da Guiné e Cabo Verde (PAIGC), fundado por Amílcar Cabral e Aristides Pereira em Setembro de 1956 (Pereira, 2002) . Há indícios de que em Dezembro daquele ano foi publicado o primeiro número do jornal Libertação, do PAIGC. Despertar as consciências e formar os militantes seriam os objectivos do jornal, policopiado e com uma tiragem de cerca de 500 exemplares, tendo circulado até 1968. ${ }^{16}$ Porém, 0 ano de 1960 também é apontado como o da fundação do jornal, e o manuscrito do editorial do $n^{0} 5$ do Libertação, escrito por Amílcar Cabral, é de Abril de 1961 (Mendy e Lobban, 2013: 467; Barros e Tchumá, 2015: 36)..17 Assinala-se ainda, acompanhando Amado (2103), a importância dos panfletos, comunicados e brochuras, de forças sociais e políticas, que circularam na Guiné, para além da importância da radiodifusão, a exemplo da clandestina Rádio Liberdade, do PAIGC.

Entretanto, a partir de 1958, o jornal passou a designar-se " 0 " Arauto, e o ${ }^{0}$ 3483 publicava a primeira intervenção do deputado da Guiné, Teixeira Mota, na

16 Nos arquivos e bibliotecas de Portugal não se encontraram exemplares do jornal Libertação. A informação da sua publicação tem origem no trabalho de Carlos Lopes, "Dois estudos e uma reflexão sociológica" (1988), o qual não cita qualquer referência arquivística ou bibliográfica do jornal.

17 "Manuscrito do editorial do jornal Libertação n. ${ }^{0} 5$ ", 1961, CasaComum.org, Disponível HTTP: http://hdl.handle.net/11002/fms_dc_41199 (2016-7-27) 
Assembleia Nacional, a qual abordava o problema do ensino e da valorização económica da província. Os colóquios sobre o II Plano de Fomento do Ultramar eram divulgados em Junho de 1959, n $n^{0} 3905$, e sublinhavam que a política de investimento deveria atender a "dualidade de economias". Em 03 Agosto de 1959 trabaIhadores africanos no porto de Bissau entraram em greve pelos baixos salários e más condições de trabalho. A reacção do governo ficou conhecida como o "massacre de Pidjiguiti", no qual foram mortos 50 trabalhadores e dezenas ficaram feridos (PAIGC, 1974). 0 Arauto fez silêncio sobre a greve e as suas consequências.

A pressão internacional e as independências africanas preocupavam o regime autoritário em Portugal, o que se reflectia na imprensa das colónias, inclusive na Guiné. "No êxito de alguns movimentos [...] assentou um programa de 'libertação' que não serve nem respeita a paz dos que não querem ser 'libertados' [...] não existem nos territórios portugueses ultramarinos quaisquer indícios de 'colonialismo'", apontava O Arauto em Junho de 1960, nº 4197.

Apesar da sua orientação governamental e pró-colonial, a edição de 10 de Abril de 1960 de 0 Arauto foi proibida de circular pela delegação local da PIDE, o que se deveu ao artigo "Carta Aberta ao Governador Geral de Angola", assinado por Ernesto Lara Filho, o qual foi "considerado prejudicial por razões de ordem políticas" (Sousa, 2010:130).

Em 1960 o estatuto indígena foi revogado e, em 1961, o trabalho forçado foi abolido. ${ }^{18}$ Contudo, na prática, pouco mudou para os africanos, em sua maioria camponeses. Apenas em 1963 foi implementado um conselho legislativo na Guiné, porém, o poder do governador manteve-se forte e dependente das decisões de Lisboa. Os serviços sociais na Guiné eram piores que nas demais colónias africanas e, em 1963, apenas 3,8\% da população em idade escolar frequentava o ensino primário e o gasto per capita em saúde era de 1,1 dólares (Rudebeck, 1974: 26-27).

Após 004 de Fevereiro de 1961 em Luanda, que assinala o princípio da luta armada na África portuguesa, 0 Arauto reforçou a defesa do império e 0 ataque aos "terroristas". Em Setembro de 1962, o nº 4856 denunciava os comunistas: "É já conhecido o recente acordo [...] que prevê, praticamente, a entrega das províncias ultramarinas, com total independência, às organizações daqueles elementos comunistas e a criação na metrópole de uma república popular". Os textos do jornal não eram assinados e a maior parte do noticiário provinha da agência Lusitânia. ${ }^{19}$

Em Janeiro de 1964, $n^{0}$ 5276, a manchete de 0 Arauto foi "De ladrões de gado a terroristas". 0 texto notava que, se até 1962 o PAIGC tinha limitado suas acções à sabotagem de linhas férreas e telefónicas, passou a ter como alvos as forças armadas portuguesas em Fevereiro de 1963. A partir de então o jornal incluiu o Boletim Informativo das Forças Armadas da Guiné (BIFAG), o qual relatava na mesma edição a destruição de acampamentos e apreensão de material de guerra do PAIGC.

A intervenção do deputado Pinto Bull na Assembleia Nacional era destacada no n ${ }^{0} 5519$, de Fevereiro de 1965, e ressaltava "os esforços titânicos que se vem fazendo na Guiné nos campos militar, económico e social". No aniversário de 0 Ar-

18 Sobre o trabalho forçado no império português ver Michel Cahen, "Indiginato Before race? Some proposals on Portuguese Forced Labour in Mozambique and The African Empire", 2012.

19 A Agência Noticiosa Lusitânia foi criada em 1944 e dissolvida em 1974. 
auto, em 05 de Julho de 1967, o jornal agradecia ao governador a concessão de 50 mil escudos. 0 texto sublinhava que em 1966 o défice do jornal era de 486 mil e questionava "se poderemos continuar a viver assim". Na sua última fase, os conteúdos de 0 Arauto estiveram centrados no combate ao comunismo e em artigos sobre os países que apoiavam Portugal. A última edição do jornal saiu em 10 de Abril de 1968, n⿳06444.

Apesar dos esforços da propaganda autoritária em construir um discurso de vitória na Guiné, em Julho de 1963 militares portugueses admitiam que o PAIGC controlava parte do território. Em Maio de 1968, António de Spínola tornou-se o chefe do Estado-maior e governador da Guiné. Spínola reforçou os trabalhos nas obras públicas e nos serviços sociais, no que pretendia ser uma abordagem "plural" da guerra, com acções políticas sociais e psicológicas. Entretanto, em 1970 o PAIGC tinha intensificado a guerra, o que acelerou as perdas portuguesas (MacQueen, 1997: 37-41).

Entre 1968-70, circulou o semanário oficial Notícias da Guiné, Boletim do Centro de Informação e Turismo. 0 n 01, em 21 de Abril de 1968, anunciava os objectivos do jornal: "fazer o registo do dia a dia da vida da portuguesa Província da Guiné". 0 BIFAG passou a ser divulgado através do Notícias da Guiné. Em Dezembro de 1968 o jornal, $n^{0}$ 45, anunciava as novas medidas do governo em Lisboa: aumento do salário mínimo, vencimentos fixos para os régulos, investimentos no campo social e a dispensa das dívidas. No ${ }^{0} 52$, de Fevereiro de 1969, o semanário informava que "As populações da área de Bigene receberam com entusiásticas manifestações de alegria a notícia dos novos êxitos obtidos pelas Forças da Ordem". A edição nº 99, de Janeiro de 1970, acusava a Europa:

A opinião pública mundial só compreenderá a razão que assiste aos portugueses em manterem intactas as suas províncias ultramarinas [...] quando compreender também o que estes territórios representam para a segurança de uma África livre.

0 n 108, em 22 de Março de 1970, foi a última edição do Notícias da Guiné.

Entre Janeiro de 1946 e Abril de 1973 o Centro de Estudos da Guiné Portuguesa (ligado à secção de estatística do governo da Guiné) publicou o Boletim Cultural da Guiné Portuguesa. 0 Boletim foi uma revista de carácter científico, com estudos de divulgação no campo da história, da etnografia, das artes e da literatura. 0 objectivo da publicação foi o "estudo sistemático da Colónia sob todos os aspectos - meio físico, meio biológico, meio humano". O periódico oficial incluiu na maioria dos seus números uma crónica de exaltação da administração colonial, dados estatísticos e uma revista de imprensa. Amílcar Cabral, na década de 1950 a trabalhar como agrónomo na Guiné e líder do PAIGC, publicou dois artigos no Boletim, ambos sobre questões agrícolas, em 1954 (Vol. IX, n 34) e 1958 (Vol. XIII, nº 51).

Note-se que ao longo do período colonial circularam ainda outras publicações impressas, editadas por grupos religiosos, por militares e por escolas, por exemplo. Os conteúdos de tais impressos estiveram ligados aos interesses destes sectores, os quais, em geral, não incluíram informações noticiosas e generalistas, para além de terem sido jornais efémeros e irregulares (Gonçalves, 1966). Em simultâneo, como noutras colónias portuguesas, também na Guiné circularam os periódicos publicados na metrópole e noutros territórios. 
Em Abril de 1972 uma missão do comité de descolonização da Organização das Nações Unidas visitou as zonas libertadas e recomendou que o PAIGC fosse reconhecido como o único representante do povo da Guiné. Amílcar Cabral foi assassinado em 20 de Janeiro de 1973 e em Março os portugueses perderam o controlo aéreo do território. Em Agosto, Spínola deixou África e em 24 de Setembro de 1973, em Madina do Boé, foi declarada a independência da República da Guiné-Bissau, presidida por Luís Cabral. Em poucas semanas, a nova nação foi reconhecida por mais de 80 países e, em 17 de Setembro de 1974, as Nações Unidas admitiram como membro a República da Guiné-Bissau.

\section{Guiné, A IMPRENSA A SERVIÇo do IMPÉRIO}

Durante 0 Estado Novo a perseguição e a censura à imprensa na Guiné foi incipiente, pois não existiu um jornalismo que questionasse, criticasse ou se opusesse às políticas autoritárias. Embora a censura à imprensa nas colónias africanas continue por estudar, e ainda que a comissão de censura controlasse os conteúdos dos jornais também na Guiné, foi rara a suspensão de títulos e a estratégia de comprar periódicos através de empresários apoiantes do regime e de capitais públicos, a exemplo do que se passou em Moçambique (llídio Rocha, 2000), não foi necessária na Guiné. Tal se explica pela ausência de uma imprensa que divergisse das directivas do regime autoritário e o confrontasse.

No caso do Comércio da Guiné, o movimento insurrecto de 1931 levou ao seu fim e o recrudescer do regime não foi propício à retomada do empreendimento. Por 13 anos a Guiné esteve sem um jornal, até que surgiu o Arauto, propriedade da Igreja, que sempre endossou as políticas do governo autoritário, na metrópole e na Guiné. Diferente do que se passou em Moçambique, onde o jornal da igreja desempenhou um papel de oposição ao Estado Novo (Capela, 1989), na Guiné a imprensa católica apoiou incondicionalmente o governo. Quando do fim do Arauto, em 1968, o governo criou 0 Notícias da Guiné, um jornal oficial ao qual cabia divulgar o regime e as suas políticas.

Tais títulos privilegiaram a propaganda ideológica do regime, o que implicou a parcialidade dos conteúdos e a divulgação de factos distorcidos, a exemplo dos Boletins das Forças Armadas e da campanha contra as forças que lutavam pela libertação da Guiné. Se a imprensa católica desempenhava uma colaboração 'voluntária' com o governo, a qual se explicava pela aliança da Igreja com o Estado Novo, com o início das guerras de libertação na África portuguesa a imprensa na Guiné passou a total instrumentalização, servindo exclusivamente ao regime autoritário, como assinalaram Siebert et al. (1953: 18): "Tais propósitos [do governo autoritário], inevitavelmente, controlam a sua atitude em relação aos aspectos culturais e políticos da comunicação. Aliás, a Constituição de 1933, de 11 de Abril, (no seu artigo $22^{\circ}$ ) tinha definido o papel do Estado em relação aos media: "A opinião pública é elemento fundamental da política e administração do País, incumbindo ao Estado defendê-la de todos os factores que a desorientem contra a verdade, a justiça, a boa administração e o bem comum".

Não se sabe quem foram e quantos eram os jornalistas na Guiné, pois os textos dos jornais não eram assinados e os títulos não tinham fichas técnicas. Note-se que uma parcela significativa dos conteúdos da imprensa dependia da agência de notícias Lusitânia, instrumento do regime, o que indica um quadro mínimo de profissio- 
nais da imprensa na Guiné. Sabe-se também que nos órgãos oficiais escreviam e colaboravam funcionários públicos alinhados ao regime ou por estes constrangidos. Não há registo de escolas de formação profissional na área da comunicação, de associações profissionais ou de normas deontológicas entre os jornalistas.

Aplicado o conceito de paralelismo político no contexto de um único jornal e de uma única força política, pode-se dizer que o paralelismo político na Guiné foi completo. Porém, havia forças sociais e interesses distintos dos do governo na Guiné e estes não tiveram qualquer expressão na imprensa. A intervenção do governo na imprensa foi forte: o governo publicou jornais e boletins de informação; subsidiou o Arauto; e controlou os conteúdos em seu favor.

\section{Legado da Imprensa Colonial}

Os processos de transição para a ordem política moderna foram graduais, e é como um regime liberal representativo numa sociedade pouco desenvolvida, nem autoritário nem democrático, que se caracteriza a Monarquia Constitucional portuguesa (Freire, 2011: 25-81). Se foi difícil ultrapassar os obstáculos à modernização em Portugal (Almeida, 1991: 25), a modernidade não se concretizou nas colónias portuguesas, inclusive porque é incompatível com a ausência de soberania, pressuposto do colonialismo.

Foi neste contexto sociopolítico - aliado aos imperativos da ocupação, do domínio do território e do desenvolvimento económico - que o império autonomizou a Guiné, deu-Ihe instituições e criou o Boletim Oficial, ao qual cabia fomentar o programa colonial. Porém, não se seguiu a criação de uma imprensa noticiosa generalista e não-oficial, o que se deveu ao incipiente desenvolvimento económico da Guiné, à fraqueza das elites e à centralidade das campanhas de 'pacificação'.

Em Portugal, a revolução republicana originou-se na aliança entre o povo e a pequena burguesia (Rosas, 2009). A democratização política, a descentralização administrativa, a extensão do sistema de ensino, a modernização económica e social, a independência da tutela externa e a atenção aos territórios africanos eram as promessas dos republicanos (Serra, 2009). Porém, o regime não foi capaz de impulsionar o desenvolvimento de Portugal e dos territórios africanos e as reformas administrativas não tiveram sucesso. Os africanos continuaram a não ser cidadãos e mantiveram-se práticas que promoviam a dualidade social, política e económica.

A fraqueza das elites coloniais na Guiné associada à incipiência do desenvolvimento capitalista e do empreendimento colonial impediu a institucionalização da imprensa como plataforma do debate público. As elites africanas, desarticuladas e condicionadas por um regime opressor, também foram incipientes e não se apropriaram da imprensa para reivindicar direitos e propagar ideais africanistas de libertação, como aconteceu noutras partes da África portuguesa e noutros espaços coloniais. ${ }^{20}$

A crise da economia colonial a partir da década de 1920, as pressões internacionais e 0 descontentamento entre as elites coloniais que desejavam autonomia estiveram entre as razões do fim da Primeira República. Salazar publicou entre 1930-34 e legislação fundamental do Estado Novo - a qual incluiu o Acto Colonial de 1930,

20 Sobre as relações entre elites crioulas, nacionalismo e imprensa ver Benedict Anderson, Imagined Communities, Reflections on the Origin and Spread of Nationalism, 1993. 
a Constituição de 1933 e o Estatuto Nacional do Trabalho. 0 "ethos" da legislação e da Constituição era "absolutamente antiliberal, antiparlamentar, antidemocrático" (Martins, 2006: 32).

0 regime autoritário consolidou-se em 1939 com um partido fraco e pouco mobilizador e com um governo de elite civil composto por académicos. 0 corporativismo foi central no modelo institucional, na ideologia, na relação com os grupos de interesse e na intervenção económica do Estado. A igreja católica actuou como matriz e suporte ideológico. A polícia política foi transformada no pilar do sistema autoritário, que reprimia a oposição clandestina enquanto os serviços de propaganda controlavam a imprensa (Pinto, 1994 e 2012). Ao longo do Estado Novo a imprensa privada sempre colaborou com o governo e quando esta deixou de existir o regime criou e instrumentalizou o seu próprio jornal.

\section{CONCLUSÃo}

Portugal virou-se para o continente africano na expectativa de sobreviver enquanto império nos séculos XIX e XX e, para tal, estendeu o seu regime político e instituições. Neste contexto, a imprensa e o jornalismo em África emergiram como entidades implementadas pelo regime colonial com 0 intuito de contribuir na afirmação do império português. Como observou Barton (1979: 2), a imprensa colonial desenvolveu-se em paralelo à imprensa europeia e adoptou o seu modelo de jornalismo. No entanto, na Guiné a imprensa apareceu tardiamente e não se consolidou como espaço de debate público, servindo invariavelmente ao poder político e ao fortalecimento do império colonial português.

Para se compreender a trajectória e o protagonismo da imprensa na Guiné no período colonial é preciso analisá-la na sua interdependência às dinâmicas sociais. 0 desempenho da imprensa na Guiné articulou-se ao conjunto das dinâmicas sociopolíticas coloniais, que lhe deram as seguintes características: 1) A imprensa privada desenvolveu-se tardiamente como reflexo da fragilidade do Estado colonial, da fraqueza das elites locais (europeias e africanas), e do prolongamento dos conflitos militares. A imprensa manteve um perfil político caracterizado pela propaganda dos governos e não pela promoção do debate no espaço público; 2) Nos três regimes políticos que perpassaram a Guiné, a imprensa sempre desempenhou um papel de colaboração. Durante o Estado Novo a imprensa desenvolveu papéis característicos dos regimes autoritários, sobretudo apoiando e propagando o regime; 3) Não houve processos de profissionalização e profissionalismo dos jornalistas; 4) Aplicado o conceito de paralelismo político, a imprensa esteve alinhada com o governo. No entanto, as distintas forças sociais não foram representadas pela imprensa; 5) A intervenção do Estado foi forte, através da propriedade, dos subsídios e do controlo dos conteúdos. 0 legado do colonialismo português para a imprensa na Guiné é 0 jornalismo enquanto actividade de suporte e apoio dos regimes e governos, e não enquanto espaço privilegiado do debate e da intervenção pública.

\section{REFERÊNCIAS BIBLIOGRÁFICAS}

Amado, Leopoldo (2013), Guineidade \& africanidade: estudos, crónicas, ensaios e outros textos, Lisboa, Edições Vieira da Silva. 
Amado, Leopoldo (2011), Guerra colonial \& guerra de libertação nacional, 1950-1974: o caso da Guiné-Bissau, Lisboa, IPAD.

Alexandre, Valentim. (1998), "A questão colonial no Portugal oitocentista", in A.H. de Oliveira Marques e Joel Serrão (dir.), Nova História da Expansão Portuguesa, Valentim Alexandre e Jill Dias (coords.), Volume XI, 0 Império Africano 1825-1890, Lisboa: Editorial Estampa, 21-132.

Alexandre, Valentim (1993), "Ideologia, economia e política: a questão colonial na implantação do Estado Novo", Análise Social, vol 28 (123-124), 1117-1136.

Almedida, Pedro T. de (1991), Eleições e Caciquismo no Portugal Oitocentista (1868-1890), Lisboa: DIFEL.

Anderson, Benedict (1983 [1986]), Imagined Communities, Reflections on the Origin and Spread of Nationalism, Londres: Verso.

Andrade, Mário P. de (1998), Origens do Nacionalismo Africano, Lisboa: Publicações Dom Quixote. Anjos, José Carlos G. dos (2006), Intelectuais, literatura e poder em Cabo Verde - lutas pelas definição da identidade nacional, Porto Alegre: Editora da Universidade Federal do Rio Grande do Sul.

Barros, Miguel de, e Tchumá, Fátima (2015), "Rádios Comunitárias e processos de recriação de cidadania ativa na Guiné-Bissau: sentidos de pertença, direito à voz e a apropriação do espaço", in Luca Bussotti, Miguel de Barros e Tilo Grätz (eds.), Media Freedom and Right to Information in Africa, Lisboa, Centro de Estudos Internacionais do Instituto Universitário de Lisboa, 31-44.

Barton, Frank (1979), The Press in Africa, Persecution and Perseverance, Londres: The Macmillan Press.

Bittencourt, Marcelo (1999), Dos Jornais às Armas, Lisboa: Vega.

CasaComum.org, Disponível HTTP: http://hdl.handle.net/11002/fms_dc_41199 (2016-7-27).

Cabaço, José Luís (2010), Moçambique - Identidades, Colonialismo e Libertação, Maputo:Marimbique.

Cahen, Michel (2012) "Indiginato Before race? Some proposals on Portuguese Forced Labour in Mozambique and The African Empire (1926-1962)", in Racism and Ethnic Relations in the Portuguese-Speaking World, Fernando Bethencourt e A. Pearce (ed.), Oxford: British Academy, 149-171.

Capela, José (1989), "Para a história do 'Diário de Moçambique'”, Revista Arquivo(06), 177-180. Capela, José (1996), "A imprensa de Moçambique até à Independência", in Fátima Ribeiro e António Sopa (eds.), 140 Anos de Imprensa em Moçambique, Maputo:Associação Moçambicana da Língua Portuguesa, 11-27.

Christians, Clifford G.; Glasser, Theodore L.; McQuail, Denis; Nordenstreng, Kaarle; White, Robert A. (2009), Normative Theories of The Media, Journalism in Democratic Societies, Chicago: University of Illinois Press.

Fonseca, Valentim C. da (1912), A Guiné a saque: documentos e factos para a história, Lisboa, Imprensa Africana.

Fonseca, Valentim C. da; Oliveira, Manuel A. (1911), Explicação ao povo da Guiné: porque pedimos a demissão de vogaes da Commissão Municipal de Bissau, Lisboa Imprensa Africana. 
Constituição de 1933, de 11 de Abril. Assembleia da República de Portugal, http://www.parlamento.pt/Parlamento/Documents/CRP-1933.pdf, acesso em 13 de Novembro de 2015.

Fonseca, Isadora de Ataíde (2014), A Imprensa e o Império na África Portuguesa, 1842-1974. Tese de Doutoramento em Sociologia da Cultura, Instituto de Ciências Sociais da Universidade de Lisboa.

Forrest, Joshua B. (1992), Guinea-Bissau, Power, Conflict, and Renewal in a West African Nation, Oxford: Westview Press.

Freire, André (2011), "Eleições, sistemas eleitorais e democratização: o caso português em perspectiva histórica e comparativa", in André Freire (cord.), Eleições e Sistemas Eleitorais no Século XX Português, Uma perspectiva Histórica e Comparativa, Lisboa: Edições Colibri, 25-81.

Gonçalves, José Júlio (1966), A informação na Guiné, em Cabo Verde e em São Tomé e Príncipe (Achegas para o seu estudo), Lisboa: Universidade Técnica de Lisboa e Instituto Superior de Ciências Sociais e Política Ultramarina.

Gunther, Richard; Mughan, Anthony (2000), "The Media in Democractic and Nondemocratic Regimes: A Multilevel Perspective", in Richard Gunther and Anthony Mughan (eds.), Democracy and the Media, A Comparative Perspective, Cambridge: Cambridge University Press.

Hallin, Daniel C. e Mancini, Paolo (2004), Comparing Media Systems, Three Models of Media and Politics, Cambridge:Cambridge University Press.

Hallin, Daniel C. e Mancini, Paolo (2012), Comparing Media Systems Beyond the Western World, Cambridge: Cambridge University Press.

Jerónimo, Miguel B. (2011), "A escrita plural dos impérios: economia, geopolítica e religião na obra de Andrew Porter", in O Imperialismo Europeu (1860-1914), Andrew Porter, Lisboa: Edições 70.

Lopes, Carlos (1988), "Dois estudos e uma reflexão sociológica", in Para uma leitura Sociológica da Guiné Bissau, Lisboa: Editorial Economia e Socialismo, 291-323.

Lopo, Júlio C. (1964), Jornalismo de Angola, Subsídios para a sua História, Luanda: Centro de Informação e Turismo de Angola.

MacQueen, Norris (1997), The Decolonization of Portuguese Africa, Essex: Longmann.

Mamdani, Mahamoud (1996), Citizen and Subject, Contemporary Africa and The Legacy of Late Colonialism, Princeton: Princeton University Press.

Marques, A. H. de Oliveira (2001), "Introdução", in A.H. de Oliveira Marques e Joel Serrão (dir.), Nova História da Expansão Portuguesa, A.H. de Oliveira Marques (coord.), Volume XI, 0 Império Africano 1890-1930, Lisboa: Editorial Estampa, 21-94.

Marques, A.H. de Oliveira (1990), História da Maçonaria em Portugal, Lisboa, Presença. Martins, Hermínio (2006 [1968]), Classe, Status e Poder, Lisboa: Imprensa de Ciências Sociais. Mendy, Peter K., e Lobban Jr., Richard A. (2013), Historical Dictionary of the Republic of

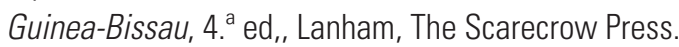

Mendy, Peter K. (1994), Colonialismo Português em África: A Tradição de Resistência na Guiné-Bissau (1879-1959), Bissau: Instituto Nacional de Estudos e Pesquisa.

Nascimento, Augusto (1999), "A Liga dos Interesses Indígenas de S. Tomé e Príncipe (19101926)", Arquipélago História, 2a série, III (1999), 417-432. 
Oliveira, João N. de (1998), A Imprensa Cabo-Verdiana, Macau: Fundação Macau Direcção dos Serviços de Educação e Juventude.

PAIGC (1974), A Guiné e as Ilhas de Cabo Verde, Porto: Afrontamento.

Pélissier, Réne (1989), História da Guiné - portugueses e africanos na senegâmbia, 18411936, volume II, Lisboa: Imprensa Universitária.

Penvenne, Jeanne (1996), "João dos Santos Albasini (1876-1922): The Contradictions of Politics and Identity in Colonial Mozambique", The Journal of African History37 (3), 419-464.

Pereira, Aristides (2002), Guiné-Bissau e Cabo Verde - Uma luta, um partido, dois países, Praia: Editorial Notícias.

Pinto, António C. (1994), Os camisas azuis - Ideologias, Elites e Movimentos Fascistas em Portugal, 1914-1945, Lisboa: Estampa.

Pinto, António C. (2012), "0 Estado Novo e o fascismo europeu", in André Freire (org.), 0 Sistema Político Português Séculos XIX-XXI, Lisboa: Almedina, 149-166.

Porter, Andrew (1994 [2011]). O Imperialismo Europeu (1860-1914), Lisboa: Edições 70.

Proença, Maria C. (2009), "A questão colonial", in Maria Fernanda Rollo and Fernando Rosas (coords.), História da Primeira República Portuguesa, Lisboa: Tinta da China, 205-228.

Reis, Célia (2001), "Guiné", in A.H. de Oliveira Marques e Joel Serrão (dir.), Nova História da Expansão Portuguesa, A.H. de Oliveira Marques (coord.), Volume X, O Império Africano 1890-1930, Lisboa: Editorial Estampa, 145-200.

Ribeiro, Maria Cristina P. (2012), Ideias republicanas na consolidação de um pensamento angolano urbano (1880 c.-1910 c.): convergência e autonomia. Tese de Mestrado em História de África. Faculdade de Letras, Departamento de História, Universidade de Lisboa.

Rocha, Aurélio (2000), "O Pan-Africanismo em Moçambique (1900-1930)", in África e a Instalação do Sistema Colonial (c. 1885 - c. 1930), III Reunião Internacional de História de África (Lisboa, Centro de Estudos de História e Cartografia Antiga do Instituto de Investigação Científica Tropical).

Rocha, Ilídio (2000), A Imprensa de Moçambique, Lisboa: Edição Livros do Brasil.

Rosas, Fernando (2009), "A crise do liberalismo oligárquico em Portugal", in Maria F. Rollo e Fernando Rosas (coord.), História da Primeira República Portuguesa, Lisboa: Tinta da China, 15-26.

Rudebeck, Lars (1974), Guinea-Bissau, A Study of Political Mobilization, Uppsala: The Scandinavian Institute of African Studies.

Semedo, Manuel B. (2003), Cabo Verde: A Construção da Identidade Nacional, Análise da Imprensa entre 1877 e 1975. Dissertação de Doutoramento, Faculdade de Letras e Ciências Sociais da Universidade Nova de Lisboa.

Serra, J.B. (2009), “0 5 de Outubro”, in Maria Fernanda Rollo e Fernando Rosas (coord.), História da Primeira República Portuguesa, Lisboa, Tinta da China, 55-60.

Siebert, Fred; Peterson, Theodore; Schramm, Wilbur (1963), Four Theories of the Press, Chicago: University of Illinois Press.

Silva, António E. D. (2010), Invenção e Construção da Guiné-Bissau, Lisboa: Almedina.

Silva, António E. D. (2008), "Sarmento Rodrigues, a Guiné e o luso-tropicalismo", Cultura, 25.

Silva, Cristina N. da, 2009, Constitucionalismo e Império, A Cidadania no Ultramar Português, Lisboa: Almedina. 
Silveira, Joel F. (1998), "Guiné”, in A.H. de Oliveira Marques e Joel Serrão (dir.), Nova História da Expansão Portuguesa, Valentim Alexandre e Jill Dias (coords.), Volume XI, O Império Africano 1825-1890, Lisboa, Editorial Estampa, pp. 21-132.

Soares, Maria João (2000), "Contradições e debilidades da política colonial guineense: 0 caso de Bissau", in Maria Emília M. Santos (ed.), África e a Instalação do Sistema CoIonial (c. 1885-c. 1930), Lisboa: Instituto de Investigação Científica Tropical e Centro de Estudos de História e Cartografia Antiga.

Sousa, Carlos T. de (2010), Crónicas de Ernesto Lara (Filho): versão integral de "Roda gigante", Lisboa, Centro de Literaturas e Culturas Lusófonas e Europeias da Faculdade de Letras da Universidade de Lisboa.

Sousa, Julião S. (2012), "As associações protonacionalistas guineenses durante a I República: o caso da Liga Guineenses e do Centro Escolar Republicano", in República e CoIonialismo na África Portuguesa, Fernando Pimenta (ed.), Porto: Afrontamento, 53-78.

Zamparoni, Vladimir D. (1988), "A Imprensa Negra em Moçambique: A Trajetória de "0 Africano" - 1908-1920", África, Revista do Centro de Estudos Africanos, 11 (1), 73-86.

Periódicos da Guiné Portuguesa

A Voz da Guiné, 1922.

Arauto, 1943-68.

Boletim Cultural da Guiné Portuguesa, 1946-1973.

Boletim Oficial da Guiné Portuguesa, 1884-1920.

Ecos da Guiné, 1920

Ecos da Guiné, 1950-54.

Pró-Guiné, 1924. 